\title{
Digital elevation models for landslide evolution monitoring: application on two areas located in the Reno River Valley (Italy)
}

\author{
Arianna Pesci $\left({ }^{1}\right)$, Paolo Baldi $\left({ }^{2}\right)$, Alessandro Bedin $\left({ }^{3}\right)$, Giuseppe Casula $\left({ }^{1}\right)$, Nicola Cenni $\left({ }^{2}\right)$, \\ Massimo Fabris $\left({ }^{3}\right)$, Fabiana Loddo $\left({ }^{1}\right)$, Paolo Mora $\left({ }^{4}\right)$ and Massimo Bacchetti $\left({ }^{2}\right)$ \\ $\left.{ }^{(}\right)$Istituto Nazionale di Geofisica e Vulcanologia, Bologna, Italy \\ (2) Dipartimento di Fisica, Settore Geofisica, Università degli Studi di Bologna, Italy \\ (3) Dipartimento di Architettura, Urbanistica e Rilevamento (DAUR), Università degli Studi di Padova, Italy \\ $\left.{ }^{4}\right)$ Dipartimento di Scienze della Terra e Geologico-Ambientali, Università degli Studi di Bologna, Italy
}

\begin{abstract}
GPS, digital photogrammetry and laser scanning techniques have been applied and compared in the frame of the studies of two complex landslides located in the Emilia-Romagna Region (Northern Italy). The three approaches, characterized by different accuracies, applicability and costs, have demonstrated to be efficient tools to define Digital Elevation Models computed in the same reference system and able to provide data on the landslide motion. The results described in the paper indicate the present low level of landslide activity in recent years. Reliability, costs and execution times of the applied surveying methods are shown and discussed in this paper.
\end{abstract}

Key words Digital Elevation Model - landslide GPS - digital photogrammetry - laser scanning

\section{Introduction}

The comparison of multitemporal Digital Elevation Models (DEMs) has been demonstrated to be a powerful tool for Earth surface deformation studies. This approach may be used to study eruptive events, gravitative instability, landslide and glacier evolution and geomorphological variations of areas subjected to crustal deformations (Achilli et al., 1997; Kaab and Funk, 1999;

Mailing address: Dr. Arianna Pesci, Istituto Nazionale di Geofisica e Vulcanologia, Via Donato Creti 12, 40128 Bologna, Italy; e-mail: pesci@bo.ingv.it
Baldi et al., 2000; Mora et al., 2003, van Westen et al., 2003). The use of DEMs provides a continuous spatial description of the process, while the classical geodetic ground-based measurements give only a sampling of deformation field at a limited number of points.

Digital Elevation Models can be obtained by means of several techniques like digital aerial and terrestrial photogrammetry, airborne and terrestrial laser scanning and GPS methodology with its different measurement approaches. Recent improvements in optical satellite imagery systems will yield stereoscopic images with a spatial resolution appropriate also for deformation monitoring in the next few years (Fraser $e t$ al., 2002).

DEMs internal accuracy is strictly related to the selected surveying method and field working conditions and depends on the morphological features of the studied area. 
The surface deformations can be detected and estimated from the direct comparison of DEMs obtained at different epochs, independently of the technique used, but at comparable accuracies. This approach requires multitemporal DEMs computed in the same reference system, to avoid a wrong interpretation of results due to systematic effects. The use of ground control points, such as natural or artificial targets located in stable areas solves the problem: they can be measured by GPS technique, providing high accuracy coordinate values (millimetre level). Applying this procedure height variation time series between DEMs can be obtained, with the aim of monitoring the dynamic surface evolution and morphological changes, evaluating the mass volumes involved after deforming events. When reference points are not available, for the registration of DEM pairs a surface matching procedure can be applied to minimize the coordinate residuals of undeformed areas by means of a roto-translation transformation between the two reference systems. The iterative least square procedure can be used for detecting deformed and stable zones (Pilgrim, 1996; Mitchell and Chadwick, 1999; Li et al., 2001).

\section{GPS technique}

The Global Positioning System (GPS) is based on the reception of a low power radio signals waves transmitted by 28 satellites distributed in a constellation around the earth. The basic principle of positioning is the computation of ranges between satellites and receivers using the different bits of information, the pseudorandom code and/or phase observables. One approach consists in measuring the temporal shift between the received signal and a replica generated by the receiver (code pseudo-range) and multiplying it by the light velocity. A second method comes from phase differences between the two signals multiplied by the wave length (phase pseudo-range): the receiver can measure only these differences and their variations in time and so a parameter, ambiguity, has to be defined. The ambiguity, in fact, represents the integer number of wavelengths contained in the satellite-receiver range at the time of first acquisition
(Hofman-Wellenof, 1997). If gaps of observation occur new ambiguities are introduced. When referring to high accuracy, GPS surveying implies the precise measurements of the vectors between two or more receivers (baselines), the so called relative positioning. Data can be acquired on static and rapid-static conditions, which require GPS stations to be stationary in time. The kinematic approach, on the contrary, allows a receiver to move with respect to one or more fixed stations, throughout the measurement sessions. The algorithms used to solve the ambiguities are quite different, based on the chosen surveying method. In the kinematic case, for example, at the beginning of the survey the ambiguities may be fixed to integer values by means of a short period (few minutes) of static observation; to maintain the knowledge of the ambiguities during motion, the On-The-Fly algorithms are generally applied (Beutler et al., 1995). Looking at practical aspects in surveying with GPS, it is important to take into account characteristics and precisions involved by the three specific approaches. The most important differences of the two static methods is the minimum observation time required, which depends on the needed accuracy, the baseline lengths, the satellite configuration and visibility, etc. Static surveying time ranges from 30 minutes to several hours, while for rapid-static applications a few minutes of observations are necessary. The accuracy decreases from millimeters to centimeters concerning the two methods. The kinematic approach allows many points to be measured in a short period of time, but with reduced accuracy with respect to static surveys. Resolving the carrier-phase ambiguities, this method is capable of yielding positions within a few centimeters in the planar and in height component (Rizos and Han, 1997).

\section{Photogrammetry}

The photogrammetric technique defines shape, size and position of objects using images taken from different points of view. Images can be acquired by analogic or digital cameras. Because digital photogrammetry processes numeric images, the available film frames must 
first be digitized and then translated from a continuous to a discrete data set. At the same time, the intensity of the signal is given by a grey or colour scale, or by the wavelength and is assigned to each pixel.

In general, using the metric properties of an image together with the coordinates of several control points, the geometry and the position of an object can be described in a defined reference frame. The processing of stereo digital images can be automatized using image matching procedures, based on well defined comparison techniques relative to shape or grey/colour intensity for the same zones (Kraus, 1998). Digital photogrammetry is able to acquire, through semi-automatic procedures, many 3D points for high spatial resolution DEMs generation, overcoming the problems of processing time and costs of the analytical approach.

The accuracy of digital photogrammetry mainly depends on the camera-object distances, images quality and on the pixel dimension, when a digital camera is used, or on the scanner resolution when an analogic camera is used. Dealing with terrestrial applications, where the distances camera-object are short (from few to some hundred meters), the precision of extracted DEMs ranges from millimeters to a few centimeters. When the photograph scale range, for instance, from 1:3000 to $1: 50000$, in the case of aerial surveys, precisions decrease from $\sim 10$ centimeters to several meters (Kraus, 1998). Obviously, the image correlation method adopted for the DEM automatic extraction plays a key role in the minimization of errors of the photogrammetric working process.

\section{Laser scanning}

The laser scanning technique, both in airborne and terrestrial applications, is based on the determination of distances between the sensor and the illuminated spot on the surface, measuring the time of flight of a laser beam, together with its orientation. For each shot of the beam the telemeter provides the distance, the reflectance and the coordinates of a surface point in a local reference system. Using a laser with high pulse repetition and a scanning mech- anism which deflects the optical beam into different directions, the system produces a set of coordinates with an irregular pattern, providing the area coverage required for the $3 \mathrm{D}$ reconstruction of the surface (Wehr and Lohr, 1999; Gordon et al., 2001).

In this work the LMS-Z210 sensor of Riegl (http://www.riegl.com), specifically designed for three-dimensional images acquisition (terrestrial applications) was adopted. A rotating mirror directs the internal laser beam over a precise angular pattern and the resulting range measurements comprise a very accurate threedimensional representation of the scene. This instrument, used in a fixed location, is an ideal tool for close range imaging applications and, in typical conditions, it works according to the parameters listed in table I. The surface is sampled with a high points density $\left(\sim 1 \mathrm{pts} / \mathrm{cm}^{2}\right)$. Different stations and the use of control points provide a complete $3 \mathrm{D}$ reconstruction of the observed area into a common reference frame.

The laser scanning precision depends on the measurement range and on the divergence of the laser beam. It is influenced by the terrain slope and its reflectance. The vegetation produces a scatter of the beam and/or illumination shadows and can reduce the quality of the terrain surface representation. Terrestrial applications provide a few centimeters accuracy, while in airborne campaigns, the expected height accuracy is to a few decimeters (Baltsavias, 1999; Casella and Spalla, 2000).

\section{The investigated areas}

These techniques were applied in a sector of the Apennines in the Emilia-Romagna Region (northern Italy). This area, which borders the southern Po Plain, is one of the most active sliding areas of the whole Italian peninsula. More than 32000 landslide bodies have been identified and 26\% of them are 'active' (Regione Emilia-Romagna, 1999; Bertolini and Pellegrini, 2001).

Many of them are classified as complex landslides (Cruden and Varnes, 1996), often involving fissured clay shales and scaly clay referred in the Italian literature to as «lithologi- 
cally and/or structurally complex rock types» (Esu, 1977).

From the kinematic point of view, most landslides are classified as multiple rotational and roto-translational slides evolving in earthflows (WP/WLI, 1993). Their reactivation generally occurs following periods of intense and/or prolonged precipitation events; in some cases snowmelt can be the triggering factor (Basenghi and Bertolini, 2001; Carboni et al., 2001).

In this work we investigated two landslide bodies located in the Reno River Valley (Bologna, Italy) (fig. 1). The first one, Ca' di Malta landslide (Mora et al., 2003), is located on the eastern slope of the Reno River Valley, $30 \mathrm{~km}$ south of Bologna. It covers an area of $\sim 40000 \mathrm{~m}^{2}$ and shows an average slope of $\sim 15^{\circ}$. The bedrock is at a mean depth of about 10 meters and it consists of in the Palombini Shale (lower Cretaceous-Cenomanian) and Varicoloured Shale (Cenomanien-Touronian) formations. The activity of this landslide has been known since 30th May 1914, when it moved, damming part of the Reno River. Following a long period of quiescence, the landslide reactivated in October 1996, when it near- ly completely dammed the river, and again in November 1998.

The Rocca Pitigliana landslide, located on the western slope of the Reno River Valley, extends for $70000 \mathrm{~m}^{2}$ with an average slope of about $13^{\circ}$. The bedrock depth and soil composition are very similar to the $\mathrm{Ca}$ ' di Malta ones. The first information about its activity dates back to 6th March 1934, when several buildings were destroyed. In April 1994 it partially reactivated, while its complete reactivation occurred in 1999 interrupting the main road. Similarly to the $\mathrm{Ca}$ ' di Malta landslide, the reactivations started with small roto-translational movements involving the crown area, subsequently evolving in earthflows.

\section{Surveying}

In order to monitor the landslide deformations and to evaluate the ground-mass involved in reactivations, a combination of the different techniques described above were applied in the frame of a research project including hydrological and geological surveys. As a

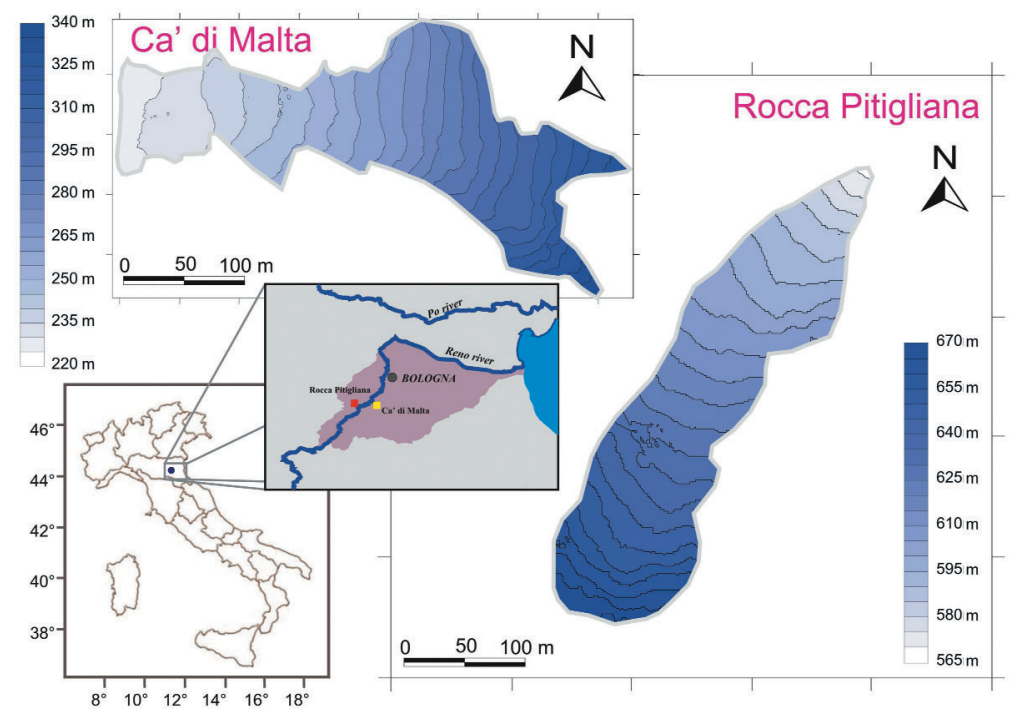

Fig. 1. Contouring of the Ca' di Malta and Rocca Pitigliana landslides and geographic location. 


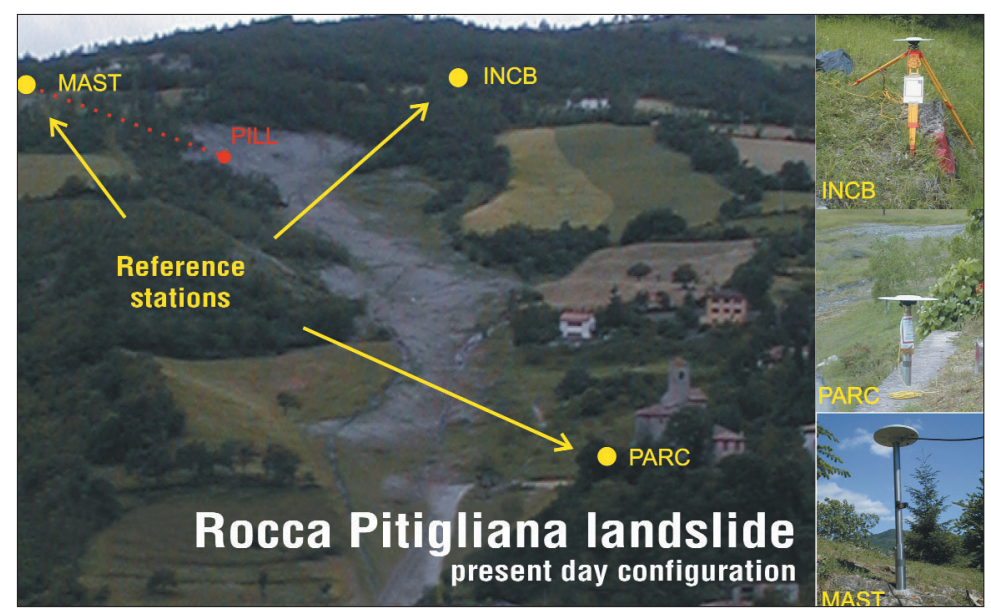

Fig. 2. Present day configuration of the Rocca Pitigliana landslide. The local GPS network is constituted by 3 stations: INCB, PARC and MAST are monumented outside the landslide area on stable buildings and rocks. PILL (red dot) is a permanent station designed to provide continuous observations together with MAST station.

first step, a local geodetic reference network was established, setting up GPS stations on the outcropping units or buildings in stable areas outside the landslide. These stations provided a reference system throughout the surveys. In fig. 2 the three stations built outside the Rocca Pitigliana landslide are shown. The stability of the reference networks was tested performing several GPS static surveys and processing the data by the software Bernese 4.2 (Rothacher, et al., 2001).

To check the activity of the landslide, many geodetic marked points were set up along the landslide body (Gili, et al., 2000; Malet et al., 2002) to detect discrete displacements between repeated surveys. The GPS vertices were placed on large boulders, partially plunged into the weathered clay-rich material, or fixed by means of $1.5 \mathrm{~m}$ long iron-pegs inserted in the terrain. Rapid-static surveys were repeated periodically; over these vertices and coordinate time series were computed. Moreover, based on static applications, significant ground points (regarding the dynamical evolution) were observed continuously to achieve real-time monitoring well suited for integration with an alert system for landslide hazard management (Mora et al., 2003).
Trimble Geomatics Office (Trimble Navigation Limited, 1999), Bernese 4.2 (Rothacher et al., 2001) and Gamit (King and Bock, 1995) software were used to process the GPS data. The GPS data show a velocity field ranging from a few to some tens of centimeters/year for the Rocca Pitigliana and Ca' di Malta landslides (Mora et. al., 2003) respectively during a time span of about six months.

\subsection{GPS kinematic surveying}

GPS kinematic surveys have been performed since November 2000 to obtain high precision DEMs of the landslides to monitor their surface changes and mass movements. The rover GPS receiver and the geodetic antenna were mounted on a telescopic pole and transported by an operator walking over the landslide surface, collecting the GPS data at 1 s sampling rate. The walking tracks were planned to cover the whole active area, leading to a high density irregular grid of points. In fig. 3a,b kinematic surveys on the Ca'di Malta and Rocca Pitigliana landslides are shown: measurements refer to campaigns carried out in No- 


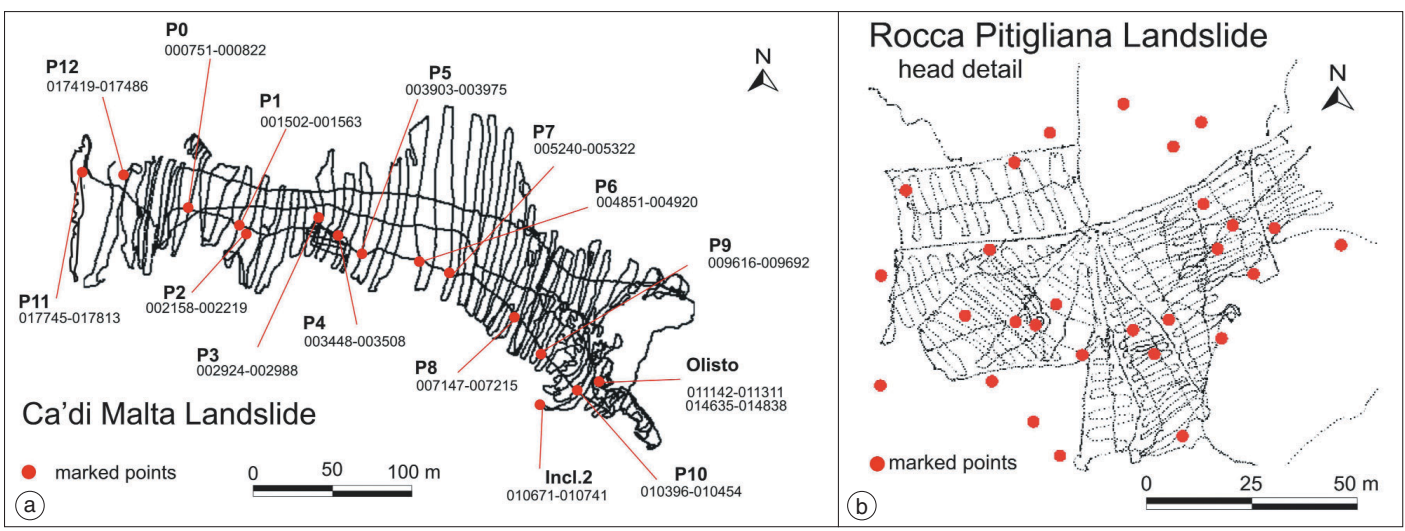

Fig. 3a,b. Kinematic surveying sketch performed over (a) the Ca' di Malta and (b) the Rocca Pitigliana landslides. In figure (a), epochs (seconds) relative to stationary acquisition are pointed out.

Table I. Statistical computation related to fig. 3a. The standard deviation is calculated for each point together with the mean height value; height residuals with respect to more accurate values (obtained from previous static surveying) are listed. Results show a good agreement between the two coordinate data sets, as pointed out by the standard deviation of differences.

\begin{tabular}{cccc}
\hline $\begin{array}{c}\text { Point } \\
\text { name }\end{array}$ & $\begin{array}{c}\text { Events } \\
\text { number }\end{array}$ & $\begin{array}{c}\text { Std }(2 \sigma) \\
(\mathrm{m})\end{array}$ & $\begin{array}{c}\text { Heigth-differences }(\mathrm{m}) \\
\text { (Kinematic-Static) }\end{array}$ \\
\hline P0 & 72 & 0.010 & 0.006 \\
P1 & 62 & 0.016 & 0.029 \\
P2 & 62 & 0.023 & 0.014 \\
P3 & 65 & 0.036 & 0.010 \\
P4 & 61 & 0.024 & 0.012 \\
P5 & 73 & 0.016 & 0.020 \\
P6 & 70 & 0.012 & -0.004 \\
P7 & 83 & 0.012 & -0.016 \\
P8 & 69 & 0.010 & 0.002 \\
P9 & 76 & 0.014 & -0.016 \\
P10 & 63 & 0.010 & -0.008 \\
P11 & 69 & 0.010 & 0.012 \\
P12 & 68 & 0.010 & -0.021 \\
Incl2 & 69 & 0.018 & -0.013 \\
Olisto & 170 & 0.018 & -0.011 \\
\hline & & & Mean $=0.001$ \\
TOTAL & 1132 & 0.020 & Std = 0.015 \\
\hline
\end{tabular}

vember 2000 and March 2003. Trimble 4700 receivers, capable of recording 2-frequency code pseudo-range and carrier phase measurements, equipped with Trimble Microcentered L1/L2 antennas, were used. The data acquisition rate assured a total coverage of the landslide with a density of about one point per square meter in the upper and more irregular zones. Reference stations were set up in stable areas close to the landslides providing baselines shorter than $500 \mathrm{~m}$.

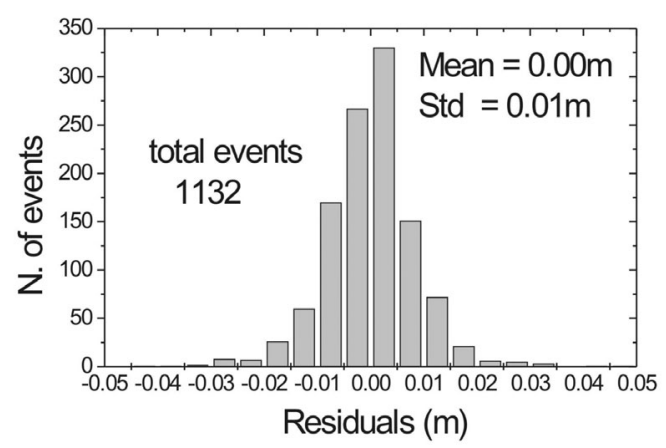

Fig. 4. Stacked histogram of height residuals with respect to the mean values of observations performed on marked points (see table I). 


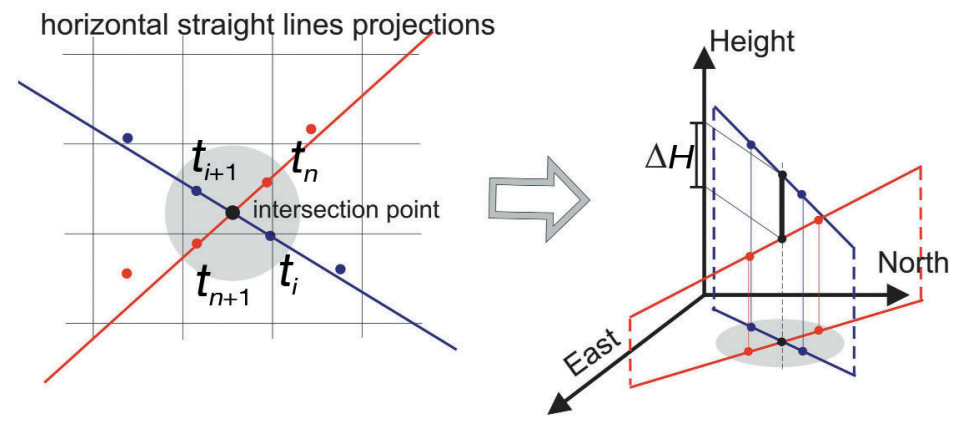

Fig. 5. Sketch of the cross-over analysis procedure.

GPS data were processed by means of Trimble Geomatics Office (Trimble Navigation Limited, 1999). In order to perform a quality control of the kinematic positioning results, some devices strictly related to the geometry acquisition system were adopted: the operator walked along longitudinal and transversal paths, stopping at GPS markers previously measured by high accuracy static surveys. The comparison between 'static coordinates' and the mean of a set of kinematic ones shows residuals of a few centimeters (table I, fig. 4).

These results are representative of kinematic precision when the rover receiver is manually fixed on a specific point for a few seconds. On the other hand, when the operator is moving, a more realistic error associated with the whole kinematic data set has to be estimated, due to the impossibility to hold the antenna vertically continuously and at a constant height from the ground. Therefore, a crossover error analysis, based on the computation of the differences of elevation at the intersection of independent track lines, can be performed. The elevation at crossover points were obtained by a linear interpolation between the nearest points of the two lines, and subsequently height differences were computed (fig. 5). The standard deviation of residuals distribution is considered representative of the data set precision. Computations show values ranging from 10 to $17 \mathrm{~cm}$ (fig. 6). Using the irregularly distributed points grid defined by the kinematic surveys, interpolated DEMs were computed (fig. 1).

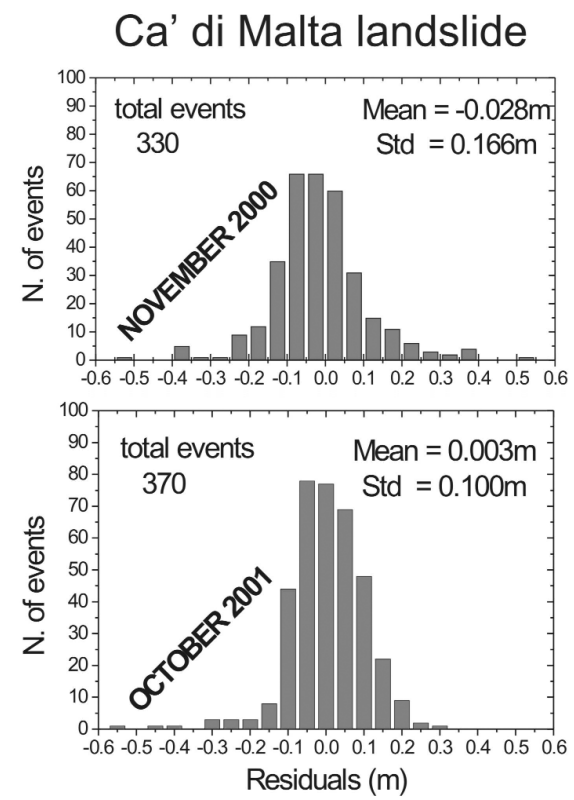

Rocca Pitigliana landslide

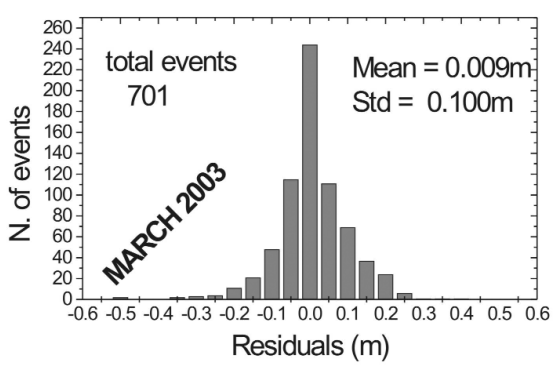

Fig. 6. Statistics of the cross-over analysis for the three kinematic data set. 


\subsection{Photogrammetric applications}

The production of photogrammetric DEMs is an important tool to study the terrain deformation. During the least decade, several aerial photogrammetric surveys have been performed from several agencies, over a large part of the Italian territory, and a large photogrammetric database is available for different epochs and scales. Normally, these photographs are film transparencies and their translation in digital images is required using high quality mechanical and optical photogrammetric scanners. Softcopy workstations, such as analytical plotters, operate in subsequent steps: orientation procedures (interior, relative and absolute), DEM generation, and ortophoto production (Shenk, 1999).
Coordinates of ground control points, referred to an external reference system and essential to orientate images, are often not available a priori. Therefore, geodetic measurement campaigns are required to measure natural points chosen on the images (corner of roof of the buildings, shoulder of bridges, corner of sidewalks, etc). Figure 7 shows an aerial photograph taken in 1976 over the Rocca Pitigliana landslide area together with fourteen control points. In this way, the whole temporal images series can be recorded in the same reference frame and, consequently, the direct comparison of extracted DEMs related to different epochs provides morphological changes. Table II shows the main features of aerial photogrammetric surveys and data processing performed over Ca' di Malta and Rocca Pitigliana land-

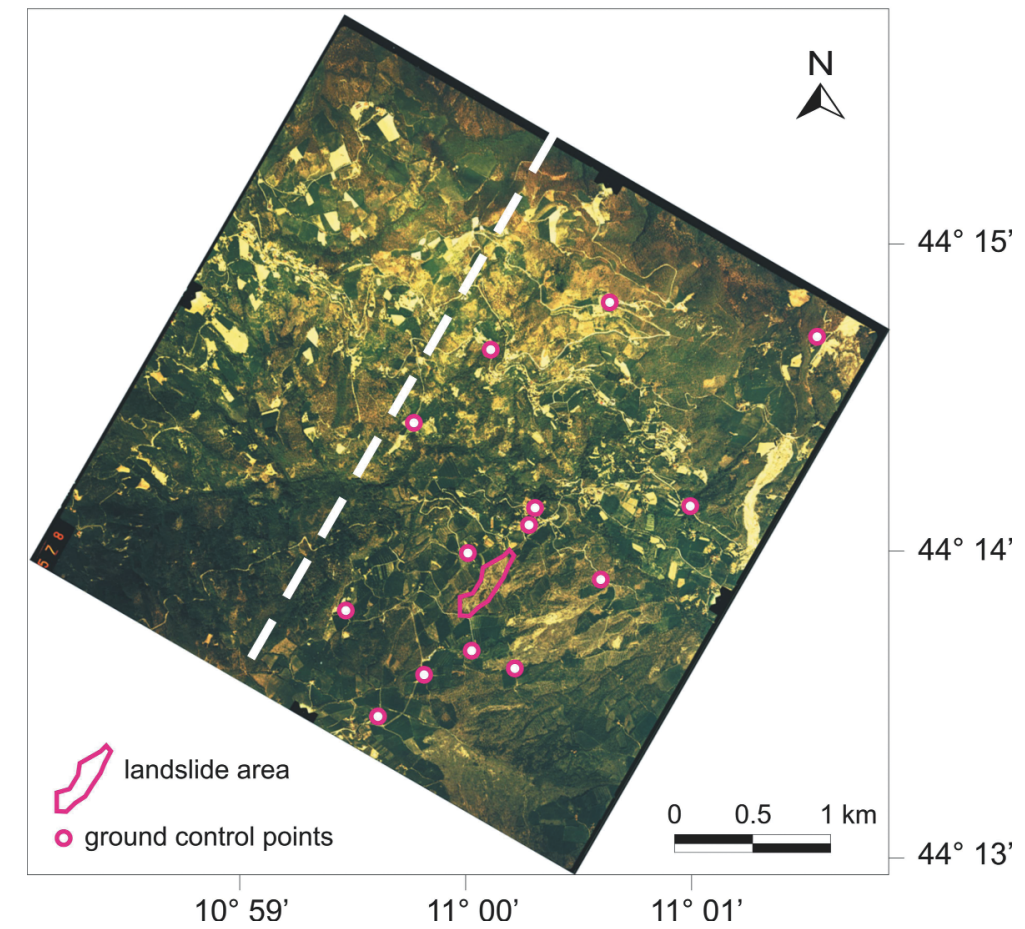

Fig. 7. Ground control points used to provide correct images orientation (1976) in the context of the Rocca Pitigliana landslide monitoring (technical features are listed in table II). It is worth nothing that all the control points lie in the right side (SE) of the image: the white dashed line, in fact, is the limit of stereo pair overlap. 
Digital elevation models for landslide evolution monitoring: application on two areas located in the Reno River Valley (Italy)

Table II. Technical details of the aerial photogrammetric surveys, reference system and scanning properties.

\begin{tabular}{lccc}
\hline \hline \multicolumn{1}{c}{ Characteristics } & 1976 flight & 1993 flight & 2000 flight \\
\hline Landslide & Rocca Pitigliana & Rocca Pitigliana & Ca' di Malta \\
Metric camera & RMK A Zeiss & RC20 Wild & RC5 Wild \\
Focal length $(\mathrm{mm})$ & 153.15 & 153.20 & 151.94 \\
Altitude $\left(^{*}\right)$ of flight $(\mathrm{m})$ & 3090 & 6015 & 940 \\
Scale (medium) & $1: 17000$ & $1: 36000$ & $1: 4500$ \\
Image number & 2 & 2 & 3 \\
Strip number & 1 & 1 & 1 \\
Longitudinal overlap & $60 \%$ & $70 \%$ & $60 \%$ \\
Monochrome or color & Color & Monochrome & Color \\
Number of ground control points & 9 & 10 & 24 \\
Reference system & UTM & UTM & UTM \\
Side aerial photograph at ground $\left(\mathrm{km}^{2}\right.$ & 3.910 & 8.280 & 1.035 \\
Coverage area at ground $\left(\mathrm{km}^{2}\right)$ & 15.288 & 68.558 & 1.071 \\
Coverage area by stereoscopic model $\left(\mathrm{km}^{2}\right)$ & 9.173 & 47.991 & 0.643 \\
Scanning photographs $(\mathrm{dpi})$ & 2116 & 2116 & 1016 \\
Pixel size $(\mu \mathrm{m})$ & 12 & 12 & 24 \\
File dimension $(\mathrm{Mb})$ & 1166 & 389 & 291 \\
Resolution at ground $(1$ pixel) $(\mathrm{cm})$ & 20 & 44 & 11 \\
\hline
\end{tabular}

(*) Altitude respect to the ground surface.

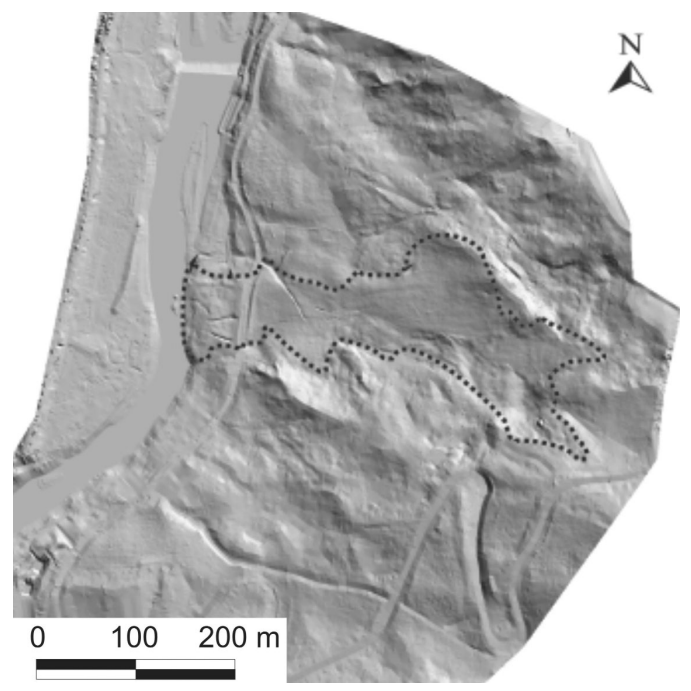

Fig. 8. Shaded relief of the Ca' di Malta landslide obtained from digital photogrammetric applications in April 2000. slides. Images were processed by means of a Digital Photogrammetric Workstation using Sun hardware and LH System SoftCopy Exploitation Tool Set (SOCET SET) software (LH System LLC, 1999). This system produces by means of an automatic image correlation a three-dimensional terrain model on a regular grid with a spacing defined by the operator. Figure 8 shows a shaded relief of the Ca' di Malta landslide. The April 2000 aerial photogrammetric survey $(1: 4500)$ led to a DEM accuracy $\sim 30 \mathrm{~cm}$.

\subsection{Laser scanning survey}

In June 2002 a survey was performed over Rocca Pitigliana landslide measuring the headscard of the landslide from two station points (fig. 9) and achieving a total coverage. High reflection coefficient targets, mounted over the GPS vertices, were used as control points to 


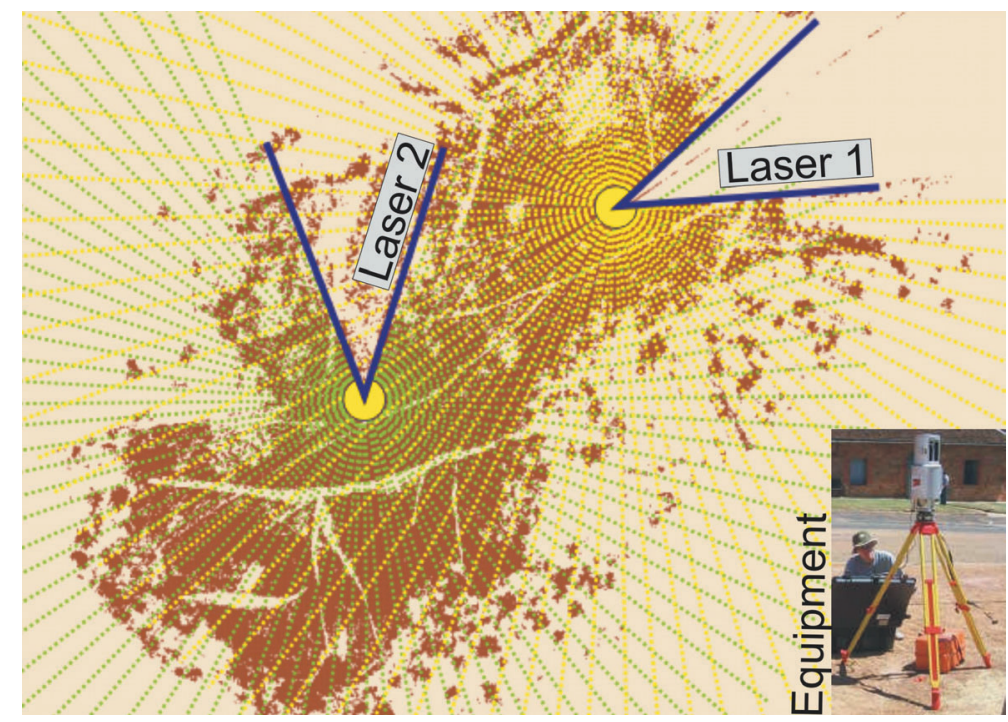

Fig. 9. Sketch of the laser scanning application performed on the Rocca Pitigliana landslide upper part (June 2002). The high density point clouds, obtained from acquisitions from two different stations, are illustred: the surveyed area includes vegetation zones, removed in a subsequent elaboration process.

register the $3 \mathrm{D}$ data in the local coordinate system. The processing was performed using the 3D RiScan software (Software Package 3DRiScan, 2003). The wide view field of the instrument together with its high scanning rate (table III), covered the area in a few minutes, acquiring a large number of data points. The result of processing was a high density DEM at a few centimeters precision.

The DEM grid was reduced to a $1 \times 1 \mathrm{~m}$ grid to perform a direct comparison with the landslide shape, obtained with GPS kinematic surveying, to check the accuracy of the methodologies adopted. It could be noticed that the area scanned by laser is not the same one shown in contouring figures, due to the presence of vegetated zones.

\section{DEMs comparisons and discussion}

The results obtained from the comparison between DEMs extracted using the above illustrated methodologies, are discussed.
Table III. Laser scanning technical data.

\begin{tabular}{|c|c|}
\hline \multicolumn{2}{|c|}{ Laser characteristics } \\
\hline $\begin{array}{l}\text { Max measurement } \\
\text { range }(\mathrm{m})\end{array}$ & $300-700$ \\
\hline $\begin{array}{l}\text { Min measurement } \\
\text { range }(\mathrm{m})\end{array}$ & 2 \\
\hline $\begin{array}{c}\text { Measurement } \\
\text { accuracy }(\mathrm{mm})\end{array}$ & 25 \\
\hline $\begin{array}{l}\text { Beam divergence } \\
\text { (mrad) }\end{array}$ & $\sim 3$ \\
\hline Field of view $\left(^{\circ}\right)$ & 80 vertical-333 horizontal \\
\hline Scanning rate (pts/s) & 6000 \\
\hline Scan time (s) & $10-240$ \\
\hline
\end{tabular}

As stated, DEMs have to be recorded in the same reference system, setting up a GPS local geodetic network in a stable area surrounding the landslide makes it possible to constrain co- 
ordinate values of stations for each GPS campaign. Concerning the photogrammetry, several ground control points a posteriori recognized on photos and external to the landslide area are measured by means of GPS. Consequently, the historical images are oriented in the same stable reference frame.

Also the laser scanning data set was registered in the same frame, due to the precise GPS measurement of the coordinates of targets at high reflection coefficient.

Each applied methodology lies against a characteristic output data set format.

Digital photogrammetry provides a regular grid and the resolution can be chosen by the user to satisfy specific requirements. GPS kinematics, on the contrary, yields an irregular grid at resolution strictly depending on the tracking paths and the sampling rate. Laser scanning data are irregularly distributed due to the measurement range, scanning rate and view field. Generally, terrestrial applications give a higher density point distribution with respect to the other surveying methods.

To perform a comparison at the same points, the geostatistic kriging method was adopted to interpolate GPS kinematic and laser scanning data sets obtaining $1 \times 1 \mathrm{~m}$ grid DEMs. Figure 10 shows the results of DEMs comparisons related to the Ca' di Malta landslide monitoring. A 3D model of the April 2000 photogrammetric survey was used as reference and compared with two GPS kinematic DEMs computed at November 2000 and October 2001. The precision of the different data sets ranges between ten centimeters and a few decimeters. Only small areas $\left(\sim 100 \mathrm{~m}^{2}\right)$ are affected by significant deformations greater than

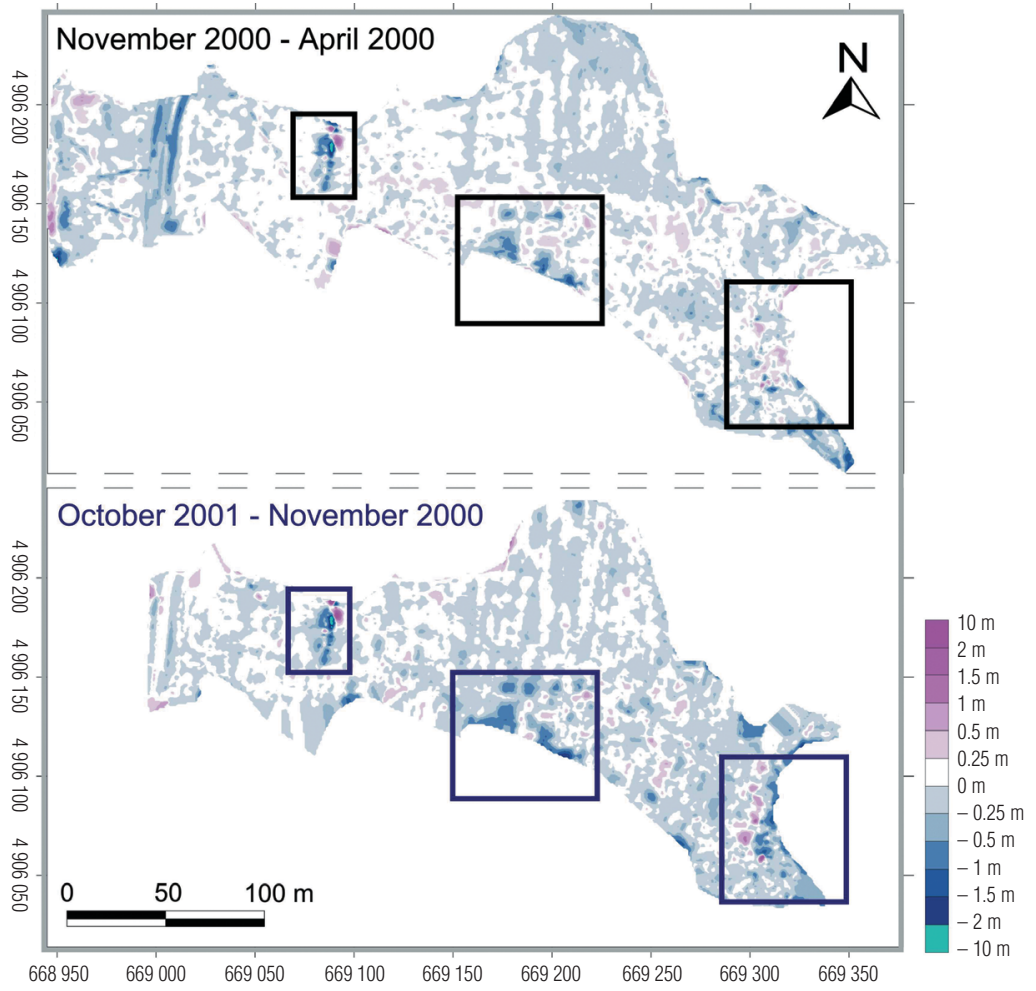

Fig. 10. Comparison of DEMs related to the Ca' di Malta landslide: models refer to April 2000 (photogrammetry), November 2000 and October 2001 (GPS). Significant variations are evidenced within rectangles. 


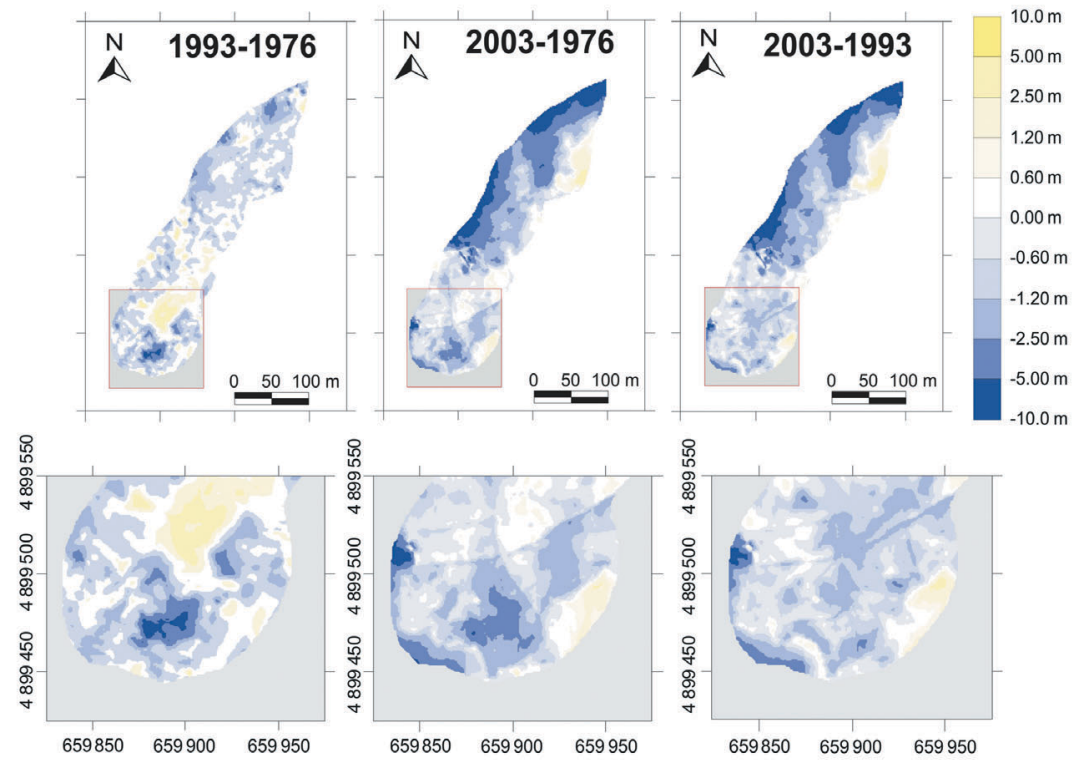

Fig. 11. Comparison of three DEMs of the Rocca Pitigliana landslide obtained from GPS (2003) and aerial photogrammetric surveys $(1993,1976)$. The selected area of investigation is defined in agreement with GPS kinematic survey. Coordinates are given in UTM cartographic reference system (metric values).

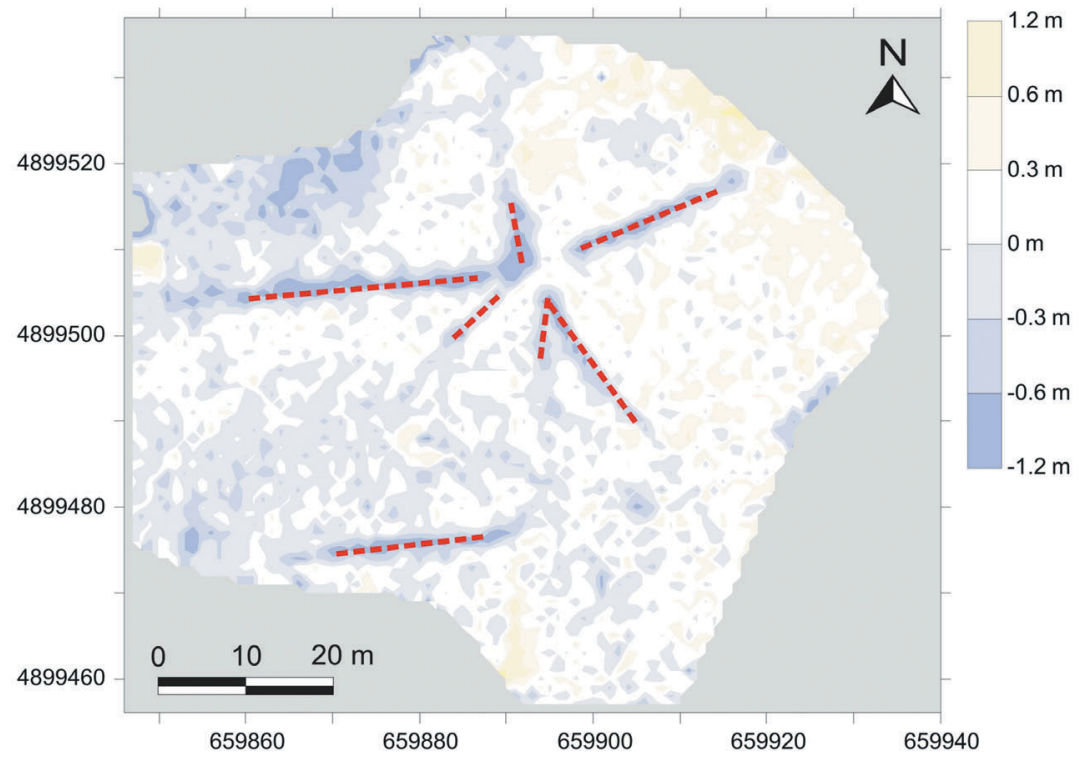

Fig. 12. DEM comparison of the upper part of the Rocca Pitigliana landslide: laser scanning (June 2002) and GPS kinematic (March 2003) data are used. The red dashed lines evidence drainage channels. 
$25 \mathrm{~cm}$. Ground lowering is correlated with local displacements mainly located around the steepest parts of the landslide. Anomalous values were measured and possibly explained by human activity or erosion phenomena. Figure 11 shows a comparison between three DEMs of Rocca Pitigliana landslide, obtained by means of GPS and aerial photogrammetry. Two models at 1976 and 1993 epochs were extracted from digital photogrammetric images, at about $50 \mathrm{~cm}$ and $1 \mathrm{~m}$ accuracy respectively. The more recent model is obtained by GPS kinematic survey and its accuracy ranges from 10 to $20 \mathrm{~cm}$. Between 1976 and 1993 a loss of mass occurred in the upper part of the landslide and the material accumulated below. Similar variations appeared during the 1976-2003 time span, while a different deformation pattern is clear between 1993 and 2003. Despite the landslide reactivated in 1994 and 1999, no relevant lowering of the ground surface at the top part was detected between 1993-2003. This apparent contrast can be explained by a pure translational motion without significant subsidence in its upper part. Remarkable lowering can be observed in the middle and lower parts, partially due to intensive excavations and remedial works that were carried out after the landslide stop. Clear evidence of human activity is detected from the comparison between June 2002 (laser scanning) and March 2003 (GPS kinematic). The drainage channels are highlighted by negative residual trends corresponding to shadow zones, where laser measurements are missing (fig. 12).

\section{Conclusions}

GPS, digital photogrammetry and laser scanning techniques have been successfully applied and compared in the frame of the landslide surface movement monitoring at $\mathrm{Ca}$ ' di Malta and Rocca Pitigliana. All these techniques are efficient tools to define landslide topography and morphological changes. The results obtained by the adopted surveying techniques are characterized by different accuracies, applicability and costs (table IV). Landslide morphology, vegetation, atmospheric environment and shadows are critical parameters and could degrade the quality of measurements.

Table IV. Applicability and precision of surveying techniques on different morphologic and atmospheric conditions: A) accessible slope: no vegetation, good atmospheric conditions; B) accessible slope: low vegetation, good atmospheric conditions; C) accessible slope: low vegetation, bad atmospheric conditions; D) not accessible slope: no vegetation, good atmospheric conditions; E) not accessible slope: low vegetation, bad atmospheric conditions.

\begin{tabular}{lcccccccccccc}
\hline \multicolumn{1}{c}{ Method } & \multicolumn{1}{c}{ Applicability } & & $\begin{array}{c}\text { Data } \\
\text { format }\end{array}$ & $\begin{array}{c}\text { Max } \\
\text { resolution }\end{array}$ & $\begin{array}{c}\text { DEM } \\
\text { accuracy }\end{array}$ & Cost \\
\hline & scale & A & B & C & D & E & & & & \\
\hline $\begin{array}{l}\text { Aerial } \\
\text { photogrammetry }\end{array}$ & $1: 5000$ & yes & $?$ & no & yes & no & Regular grid & $6-12 \mathrm{~cm}$ & $20-30 \mathrm{~cm}$ & high \\
& $1: 35000$ & yes & $?$ & no & yes & no & Regular grid & $0.5-1.0 \mathrm{~m}$ & $>1.0 \mathrm{~m}$ & high \\
$\begin{array}{l}\text { Terrestrial } \\
\text { photogrammetry }\end{array}$ & $1: 500$ & yes & $?$ & $?$ & $?$ & $?$ & Regular grid & $7-15 \mathrm{~mm}$ & $\sim 3 \mathrm{~cm}$ & low \\
\hline Terrestrial laser scanning & yes & $?$ & $?$ & $?$ & $?$ & Irregular grid & $\sim 0.5 \mathrm{~cm}$ & $<5 \mathrm{~cm}$ & low \\
\hline Aerial laser scanning & yes & $?$ & no & yes & no & Irregular grid & $\sim 10 \mathrm{~cm}$ & $>10 \mathrm{~cm}$ & high \\
\hline GPS kinematic & yes & yes & yes & no & no & Irregular grid & $\sim 20 \mathrm{~cm}$ & $\sim 10 \mathrm{~cm}$ & low \\
\hline
\end{tabular}


The requirements for GPS kinematic surveying are the absence of physical obstacles preventing satellite visibility and landslide accessibility: up to about $5000 \mathrm{~m}^{2} / \mathrm{h}$ can be surveyed by an operator.

Aerial photogrammetry is highly sensitive to vegetation coverage which hides ground surface and prevents images correlation. Only free surfaces can be modelled at high accuracy. While historical sets of photos have low costs, the execution of ad hoc aerial photogrammetric surveys is rather expensive. This technique can be applied only on good weather conditions avoiding clouds or thick ground fog. Terrestrial laser scanning provides a very large amount of measured points by means of very fast and cheap operational procedures. Generally, multiple acquisitions from different view points are executed to cover the entire area, reducing data gaps due to illumination shadows; vegetation coverage and woody zones cause a loss of data.

The main characteristics of each technique make it possible to conceive an integrated system, based on DEMs comparisons. The GPS satisfies the demand for real time monitoring at low cost and high accuracy (decimetre level). Digital photogrammetry enlarges the time and spatial domain of investigation, using also historical images with precision strictly depending on the scale of the images. Terrestrial laser scanning assures the description of restricted zones with very high spatial accuracy.

The comparison between multi-temporal models corresponding to different epochs makes it possible to determine displacements of parts of an active slide. The results described in the paper show the present low level of landslide activity, the reliability, costs and execution times of the surveying methods.

\section{Acknowledgements}

This research was developed in the context of MIUR 2001 («Controllo di fenomeni di dissesto idrogeologico in aree urbanizzate e di particolare rilevanza storico-artistica mediante l'integrazione di tecniche di telerileva- mento e di monitoraggio») and MURST 2000 ( «Soil stress-strain analysis to study the occurrence of local instabiblities and their amplification at global scale») projects.

The authors would like to thank Aldo Fantini (Comunità Montana Alta e Media Valle del Reno, Vergato, Bologna) and Cristiano Guidi (Dipartimento Fisica, Settore Geofisica, Università degli Studi di Bologna) for the GPS network monumentation and for assistance during the GPS surveys.

\section{REFERENCES}

Achilli, V., P. Baldi, L. Baratin, C. Bonini, E. Ercolani, S. GANDOLFI, M. ANZIDEI and F. RiguZZI (1997): Digital photogrammetric survey on the island of Vulcano, Acta Vulcanol., 9 (2), 1-5.

Baldi, P., S. Bonvalot, P. Briole and M. Marsella (2000): Digital photogrammetry and kinematic GPS for monitoring volcanic areas, Geophys. J. Int., 142 (3), 801-811.

BALTSAVIAs, E.P. (1999): Airborne laser scanning: basic relations and formulas, ISPRS J. Photogramm. Remote Sensing, 54, 199-214.

BASENGHI, R. and G. BERTOLINI (2001): Ricorrenza e caratteristiche delle frane riattivate durante il XX secolo nella provincia di Reggio Emilia Appennino settentrionale, Quad. Geol. Appl., 8 (1), 153-162.

Bertolini, G. and M. Pellegrini (2001): The landslides of the Emilia Apennines (Northern Italy) with reference to those which resumed activity in 1994-1999 period and required Civil Protection interventions, Quad. Geol. Appl., 8 (1), 27-74.

Beutler, G., G.W. Hein, W.G. Melbourne and G. Seeber (1995): GPS trends in precise terrestrial, airborne, and spaceborn applications, Int. Assoc. Geod. Symp., 115, 275-338.

Carboni, R., N. Casagli, A. Iotti, L. Monit and U. TARCHIANI (2001): La frana di Ca' di Sotto (San Benedetto Val di Sambro, Bologna): caratteri geomorfologici, analisi geotecniche ed interventi di mitigazione del rischio, Ouad. Geol. Appl., 8 (1), 93-106.

Casella, V. and A. Spalla (2000): Estimation of planimetric accuracy of laser scanning data. Proposal of a method exploiting ramps, ISPRS, XXXIII, Part B3/1, 157-163.

CRUdEn, D.M. and D.J. VARnES (1996): Landslides: investigation and mitigation, in Landslides Investigation and Mitigation, edited by A.K. TURner, R.L. SchusTER (Washington, DC), National Research Council, Transportation Research Board Special Report, 247, 36-75.

Esu, F. (1977): Behaviour of slopes in structurally complex formations, in Proceedings of the International Symposium TEH Geotechnics of Structurally Complex Formations, Capri, Italy (AGI, Roma), 2, 292-304.

Fraser, C.S., E. Baltsavias and A. Gruen (2002): Pro- 
cessing of Ikonos imagery for submetre 3D positioning and building extraction, ISPRS J. Photogramm. Remote Sensing, 56, 177-194.

Gili, J.A., J. COROMINAS and J. Rius (2000): Using global positioning system techniques in landslide monitoring, Engineering Geology, 55, 167-192.

Gordon, S., D. Lichti and M. STEWART (2001): Application of a high-resolution, ground-based laser scanner for deformation measurements, in 10th FIG International Symposium on Deformation Measurements, 23-32 (on line: http://rincon.gps.caltech.edu/FIG10sym/pdf/Session\%20I_Paper\%204.pdf).

Hofman-Wellenhof, B., H. Lichtenegger and J. Collins (1997): GPS Theory and Practice (Springer Verlag Wien, New York), 214-258.

KAAB, A. and A. FunK (1999): Modelling mass balance using photogrammetric and geophysical data: a pilot study at Griesgletscher, Swiss Alps. J. Glaciol., 45 (151), 575-583.

KING, R.W. and Y. Bock (1995): Documentation for the MIKT GPS Analysis Software: GAMIT, Version 10.01 (Mass. Inst. of Techn., Cambridge).

KraUs, K. (1998): Fotogrammetria (Levrotto \& Bella, Torino), 445-496.

LH SYSTEMS LLC (1999): SOCET SET-User's Manual (LH Systems, LLC, San Diego)

LI, Z., Z. XU, M. CEN and X. Ding (2001): Robust Surface Matching for Automated Detection of Local Deformations Using Least-Median-of-Squares Estimator, Photogramm. Eng. Remote Sensing, 67 (11), 1283-1292.

Malet, J.P., O. Maquaire and E. Calais (2002): The use of Global Positioning System techniques for the continuous monitoring of landslides-application to the SuperSuaze earthflow (Alpes-de Haute-Provence France), Geomorphol., 43, 33-54.

Mitchell, H.L. and R.G. CHADWick (1999): Digital photogrammetric concepts applied to surface deformation studies, Geomatica, 53 (4), 405-414.

Mora, P., P. Baldi, G. Casula, M. Fabris, M. Ghiotti, E. Mazzini and A. Pesci (2003): Global Positioning Systems and digital photogrammetry for the monitoring of mass movements: application to the $\mathrm{Ca}$ ' di Malta landslide (Northern Apennines, Italy), Eng. Geol., 68, 103-121.

PILGRIM, L.J. (1996): Surface matching and difference detection without the aid of control points, Surv. Rev., 33, 291-304.

Regione Emilia-Romagna (1999): I Numeri sulle Frane (Pendragon, Bologna), 1-94

Rizos, C. and S. HaN (1997): Status and trends for high precision GPS kinematic positioning, 1-18 (on line: (http://www.gmat.unsw.edu.au/snap/work/pdf/kinematic_gps.pdf).

Rothacher, M., G. Beutler, H. Bock, E. Brockmann, R. Dach, P. Fridez, W. Gurtner, U. Hugentobler, D. Ineichen, J. Johnson, M. Meindl, L. Mervart, S. SCHAER, T. SPRINGER and R. Weber (2001): Bernese GPS Software Version 4.2, edited by U. HUGENTOBLER, S. SCHAER and P. Fridez (on line: http://www.civil. uwaterloo.ca/hydrology/BERNESE/Bernese_4.2_Gui de.pdf).

SCHENK, T. (1999): Digital Photogrammetry (TerraScienze, Laurelville, OH), vol. 1, 41-76.

SoftwARE PACKAGE 3D-RIScAN (2003): Software Package 3D-RiScan acquisition, visualization, and processing of LMS-Z210, LMS-Z360 and LMS-Z420 data (on line: http://www.riegl.com/ 834628/ 43349805. pdf).

Trimble NAVIGATION Limited (1999): Guide to the Trimble Geomatics Office Sample Data (Trimble Navigation, Sunnyvale, CA).

van Westen, C.J. and F. Lulie Getahun (2003): Analyzing the evolution of the Tessina landslide using aerial photographs and digital elevation models, Geomorphol., 54, 77-89.

WEHR, A. and U. LOHR (1999): Airborne laser scanning - an introduction and overview, ISPRS J. Photogramm. Remote Sensing, 54, 68-82.

WP/WLI (1993): A suggested method for describing the activity of a landslide, Bull. Int. Assoc. Eng. Geol., 47, 53-57.

(received February 10, 2004 accepted July 15, 2004) 